\title{
Comparison of Obesity and Its Relationship to Some Metabolic Risk Factors of Atherosclerosis in Arabs and South Asians in Kuwait
}

\author{
Pavel Babusik ${ }^{a} \quad$ Ivan Duris ${ }^{b}$ \\ ${ }^{a}$ Department of Internal Medicine, Al Rashid Hospital, Kuwait; ${ }^{b}$ Medical Faculty of Comenius University, \\ Bratislava, Slovak Republic
}

\section{Key Words}

Arabic and South Asian ethnicity · Kuwait • Obesity • Metabolic cardiovascular risk factors

\begin{abstract}
Objective: The aims of the study were to compare obesity and its association with risk factors of atherosclerosis in Arabs and South Asians in Kuwait and to define which of the anthropometric parameters is best suited for clinical purposes in general. Subjects and Methods: Two hundred eighty adults, patients of Al-Rashid Hospital, a private general hospital in Kuwait, were enrolled in the study. Of the 280 patients, 144 were Arab and 136 were South Asian. Basic anthropometric parameters for obesity, fasting blood glucose, total cholesterol, low-density lipoprotein and high-density lipoprotein cholesterol and triglycerides (TG) were determined. The relationship between anthropometric variables and relevant metabolic variables, as well as a comparison between the different groups, was estimated using standard statistical methods. Results: Arabs were not only more obese [in males, $\mathrm{p}<0.001$ for body mass index (BMI), waist circumference (WC) and hip circumference $(\mathrm{HC})$ and $p=0.001$ for waist-to-hip ratio (WHR); in females, $\mathrm{p}<0.001$ for $\mathrm{BMI}, \mathrm{p}=$ 0.004 for $\mathrm{WC}$ and $\mathrm{p}=0.041$ for $\mathrm{HC}$, but also developed obesity at a younger age than did South Asians, even though, in South Asians, all anthropometric parameters were positively correlated with age ( $p=0.004$ for $\mathrm{BMI}, \mathrm{p}=0.001$ for $\mathrm{HC}$ and
\end{abstract}

$p<0.001$ for WC and WHR). South Asians, however, were more prone to develop adverse effects in both lipid and glucose metabolism than Arabs were. In South Asian males, ethnicity was an independent predictor of triglycerides, according to the multiple linear regression analysis. The WHR appeared to be the most suitable predictor of dyslipidemia and impaired glucose metabolism. Conclusion: The degree of adiposity was different between Arabs and South Asians in Kuwait. Abdominal obesity had a different impact on cardiovascular risk factors in these two ethnic groups in Kuwait.

Copyright $\odot 2010$ S. Karger AG, Basel

\section{Introduction}

Obesity has been reported to have a different impact on metabolic risk factors in different ethnic groups [1-6]. Until recently, the cutoff points for defining obesity were derived from studies related to the Caucasian population of the western world. The lack of adequate information and recommendations on this issue has been recognized, and new cutoff points for parameters of obesity for different populations have been recommended [7-10]. Ethnic Arabs, together with South Asians (people originating from the Indian Subcontinent), constitute a major portion of the residents of Kuwait. According to the author's current knowledge (based on a search of online databases), these two groups have not yet been compared by

\section{KARGER \\ Fax +4161306 1234 \\ E-Mail karger@karger.ch}

www.karger.com
(C) 2010 S. Karger AG, Basel

$1011-7571 / 10 / 0194-0275 \$ 26.00 / 0$

Accessible online at:

www.karger.com/mpp
Dr. Pavel Babusik, $\mathrm{PhD}$

Nam. S. Moysesa 2A

SK-974 01 Banska Bystrica (Slovak Republic)

Tel. +421 90786 6319, E-Mail paba54@ hotmail.com 
means of anthropometric parameters for obesity and its impact on the metabolic risk factors of atherosclerosis. Hence, the aim of this study was to determine the difference in the impact of obesity on Arabs versus South Asians in Kuwait.

\section{Subjects and Methods}

\section{Cohort of Patients}

Patients recruited for this study from the medical clinic in $\mathrm{Al}-$ Rashid Hospital, a private general hospital in Kuwait, during the period of March 2004 to November 2007, underwent screening for fasting blood glucose (FBG) and blood lipids. The inclusion criteria were: Arab or South Asian ethnic group and absence of medical conditions with a potential effect on the studied anthropometric and biochemical parameters (apart from obesity and the common components of metabolic syndrome). The exclusion criterion was: current consumption of any medication with a potential to influence the studied parameters. Ethnicity was assigned based on the country of origin and the patient's statement of the ethnicities of both parents. The patients' ages ranged from 18 to 69 years, respectively. The total number of participants was 280, comprised of 144 Arabs and 136 South Asians. Of the Arab patients, 67 were male and 77 were female. Of the South-Asian patients, 113 were male and 23 were female.

\section{Anthropometric Measurements and Biochemical Analysis}

All anthropometric measurements were performed by two skilled and properly instructed nurses (D.G., J.M.). Body weight and height were measured using a Seca digital scale and a measuring rod of the Seca scale, respectively. Waist circumference (WC) was defined as the smallest circumference along the distance between the lower edge of the rib cage and the upper edge of the iliac crest. Hip circumference (HC) was defined as the largest circumference at, approximately, the level of the greater trochanter. An unstretchable measuring tape was used for obtaining the measurements. Samples of blood glucose and blood lipids after 14hour overnight fasting were collected and analyzed. The analysis was conducted in the hospital laboratory, which is under the external quality control of Randox, GB. For glucose analysis, a hexokinase reaction was used. Total cholesterol (TC) and triglycerides (TG) were tested using the enzymatic method. The homogenization method was used to test the high-density-lipoprotein cholesterol (HDL). Low-density-lipoprotein cholesterol (LDL) was calculated using Friedewald's equation.

\section{Statistical Analysis}

All statistical analyses were conducted using the Statistical Package for Social Sciences, v. 15.0 (SPSS Inc., Chicago, Ill., USA). Five percent was used as the threshold for statistical significance. Data are reported as means \pm the standard deviation. Comparisons between groups were analyzed using an independent-samples $t$ test. Natural logarithms of the variables of body mass index (BMI), FBG, HDL and TG were used because of their skewed nature. Pearson correlation coefficients were determined for BMI, WC, HC, waist-to-hip ratio (WHR), and cardiovascular-disease (CVD) risk factors within each gender and ethnicity.
Partial correlation was used to adjust the above relations for age and gender within each ethnicity. Multiple linear regression analyses were performed within each gender, with various CVD risk factors as dependent variables and BMI and ethnicity or WHR and ethnicity or WC and ethnicity or HC and ethnicity as the independent variables. The regression analyses were adjusted for age.

\section{Results}

The general characteristics of Arabs and South Asians within each gender are shown in table 1. In Arabs and South Asians, age was not significantly different within each gender $(41.9 \pm 11.4$ vs. $41.2 \pm 9.0$ years, $p=0.7$ for males and $44.7 \pm 12.1$ vs. $48.2 \pm 10.6$ years, $p=0.25$ for females). Hence, the groups were comparable. There were highly significant differences between Arabs and South Asians in all anthropometric measurements among males $(0.97 \pm 0.06$ vs. $0.94 \pm 0.06, p=0.001$ for WHR; $32.4 \pm 7.6$ vs. $26.2 \pm 4.3, \mathrm{p}<0.001$ for BMI; $107 \pm 16$ vs. $92 \pm 12 \mathrm{~cm}, \mathrm{p}<0.001$ for WC; and $110 \pm 13$ vs. $98 \pm 10$ $\mathrm{cm}, \mathrm{p}<0.001$ for HC). Among females, the difference in WHR was not significant $(0.94 \pm 0.06$ vs. $0.91 \pm 0.07$, $\mathrm{p}=0.06)$ and the level of significance was lower for HC $(113 \pm 14$ vs. $107 \pm 13 \mathrm{~cm}, \mathrm{p}=0.041)$ and WC $(106 \pm 14$ vs. $97 \pm 12 \mathrm{~cm}, \mathrm{p}=0.004)$. Arabs had higher values than South Asians did in all of the mentioned anthropometric measures within each gender. Of the metabolic parameters tested, only TG levels were significantly higher in South Asians than in Arabs, among men (1.82 \pm 0.95 vs. $2.19 \pm 1.17 \mathrm{mmol} / \mathrm{l}, \mathrm{p}=0.039)$. CVD risk factors were not significantly different in Arabs and South Asians, among women.

Among Arabs, WC was positively correlated with FBG ( $r=0.176, p=0.043)$, while WHR was positively correlated with FBG $(\mathrm{r}=0.241, \mathrm{p}=0.005)$ and $\mathrm{TG}(\mathrm{r}=0.178$, $\mathrm{p}=0.050)$ and negatively correlated with HDL $(\mathrm{r}=$ $-0.228, p=0.013$; table 2). In South Asians, WC was positively correlated with FBG $(r=0.182, p=0.035)$ and TC/ HDL ratio $(r=0.239, p=0.027)$, while WHR was positively correlated with FBG $(\mathrm{r}=0.259, \mathrm{p}=0.002)$, TC $(\mathrm{r}=$ $0.276, p=0.010), \mathrm{LDL}(\mathrm{r}=0.322, \mathrm{p}=0.003), \mathrm{TG}(\mathrm{r}=0.221$, $\mathrm{p}=0.042)$ and TC/HDL ratio $(\mathrm{r}=0.344, \mathrm{p}=0.001)$. The negative correlation of WC with HDL was not statistically significant. In South Asians, there were strong positive correlations between age and all anthropometric measures. In Arabs, such correlations were not observed, except for the positive correlation between age and WHR.

When controlled for gender and age using partial correlation, significant correlations of WC with FBG and of 
Table 1. Characteristics of the studied sample according to gender and nationality

\begin{tabular}{|c|c|c|c|c|c|c|}
\hline \multirow[t]{2}{*}{ Variable } & \multicolumn{3}{|l|}{ Male } & \multicolumn{3}{|l|}{ Female } \\
\hline & $\begin{array}{l}\text { Arabs } \\
(\mathrm{n}=67)\end{array}$ & $\begin{array}{l}\text { South Asians } \\
(\mathrm{n}=113)\end{array}$ & $\mathrm{p}$ value & $\begin{array}{l}\text { Arabs } \\
(\mathrm{n}=77)\end{array}$ & $\begin{array}{l}\text { South Asians } \\
(\mathrm{n}=23)\end{array}$ & $\mathrm{p}$ value \\
\hline Age, years & $41.9 \pm 11.4$ & $41.2 \pm 9.0$ & 0.703 & $44.7 \pm 12.1$ & $48.2 \pm 10.6$ & 0.247 \\
\hline $\mathrm{BMI}, \mathrm{kg} / \mathrm{m}^{2}$ & $32.4 \pm 7.6$ & $26.2 \pm 4.3$ & $<0.001$ & $35.6 \pm 6.7$ & $29.1 \pm 5.2$ & $<0.001$ \\
\hline $\mathrm{WC}, \mathrm{cm}$ & $107 \pm 16$ & $92 \pm 12$ & $<0.001$ & $106 \pm 14$ & $97 \pm 12$ & 0.004 \\
\hline $\mathrm{FBG}, \mathrm{mmol} / \mathrm{l}$ & $7.19 \pm 3.75$ & $7.04 \pm 2.43$ & 0.760 & $7.09 \pm 3.82$ & $6.45 \pm 1.95$ & 0.620 \\
\hline $\mathrm{TC}, \mathrm{mmol} / \mathrm{l}$ & $5.38 \pm 0.95$ & $5.69 \pm 0.93$ & 0.074 & $5.39 \pm 1.06$ & $5.18 \pm 1.36$ & 0.461 \\
\hline $\mathrm{HDL}, \mathrm{mmol} / \mathrm{l}$ & $1.05 \pm 0.25$ & $1.03 \pm 0.19$ & 0.876 & $1.23 \pm 0.32$ & $1.15 \pm 0.28$ & 0.309 \\
\hline $\mathrm{LDL}, \mathrm{mmol} / \mathrm{l}$ & $3.69 \pm 0.94$ & $3.83 \pm 0.96$ & 0.416 & $3.59 \pm 0.96$ & $3.16 \pm 1.11$ & 0.091 \\
\hline $\mathrm{TG}, \mathrm{mmol} / \mathrm{l}$ & $1.82 \pm 0.95$ & $2.19 \pm 1.17$ & 0.039 & $1.57 \pm 0.75$ & $1.99 \pm 1.46$ & 0.295 \\
\hline
\end{tabular}

$\mathrm{p}$ values are generated by $\mathrm{t}$ test to compare between males and females. Natural logarithms of the variables BMI, FBG, HDL and TG were used because of their skewedness.

Table 2. Correlation of BMI, WC, HC and WHR with quantitative variables according to nationality

\begin{tabular}{|c|c|c|c|c|c|c|c|c|}
\hline & \multicolumn{2}{|l|}{ BMI } & \multicolumn{2}{|l|}{ WC } & \multicolumn{2}{|l|}{$\mathrm{HC}$} & \multicolumn{2}{|l|}{ WHR } \\
\hline & $\mathrm{r}$ & $\mathrm{p}$ value & $\mathrm{r}$ & $\mathrm{p}$ value & $\mathrm{r}$ & $\mathrm{p}$ value & $\mathrm{r}$ & $\mathrm{p}$ value \\
\hline FBG & 0.125 & 0.149 & 0.176 & 0.043 & 0.070 & 0.423 & 0.241 & 0.005 \\
\hline $\mathrm{TC}$ & 0.048 & 0.601 & -0.017 & 0.855 & 0.008 & 0.930 & -0.035 & 0.707 \\
\hline $\mathrm{HDL}$ & 0.035 & 0.708 & -0.085 & 0.359 & 0.022 & 0.816 & -0.228 & 0.013 \\
\hline TC/HDL ratio & -0.036 & 0.695 & 0.032 & 0.734 & -0.033 & 0.724 & 0.148 & 0.112 \\
\hline Age & -0.003 & 0.969 & 0.083 & 0.327 & 0.024 & 0.781 & 0.169 & 0.045 \\
\hline \multicolumn{9}{|l|}{ South Asians } \\
\hline FBG & 0.053 & 0.544 & 0.182 & 0.035 & 0.058 & 0.506 & 0.259 & 0.002 \\
\hline $\mathrm{TC}$ & 0.057 & 0.599 & 0.177 & 0.101 & 0.021 & 0.849 & 0.276 & 0.010 \\
\hline Age & 0.247 & 0.004 & 0.378 & $<0.001$ & 0.285 & 0.001 & 0.307 & $<0.001$ \\
\hline
\end{tabular}

WHR with TG disappeared in Arabs, while a correlation remained between WHR and FBG $(r=0.222, \mathrm{p}=0.011)$ in this group (table 3). In South Asians, significant correlations of WC with FBG and of WHR with TC and TG disappeared, while the significance of the correlations of WC with the TC/HDL ratio $(\mathrm{r}=0.346, \mathrm{p}=0.001)$ and with $\mathrm{TG}(\mathrm{r}=0.214, \mathrm{p}=0.054)$ was improved. The correlations remained between WHR and FBG $(r=0.171, p=0.050)$,
LDL $(\mathrm{r}=0.232, \mathrm{p}=0.041)$ and $\mathrm{TC} / \mathrm{HDL}$ ratio $(\mathrm{r}=0.347$, $\mathrm{p}=0.001)$. The correlation of WHR with HDL became significant $(\mathrm{r}=-0.220, \mathrm{p}=0.047)$.

The results of the multiple linear regression analyses for males and females, respectively, are shown in table 4 . Among males, ethnicity was an independent predictor for $\log$ TG, after adjusting for any one of the anthropometric measures BMI, WC, WHR or HC, independently 
Table 3. Partial correlation of BMI, WC, $\mathrm{HC}$ and WHR with quantitative variables, controlling for age and sex according to nationality

\begin{tabular}{|c|c|c|c|c|c|c|c|c|}
\hline & \multicolumn{2}{|l|}{ BMI } & \multicolumn{2}{|l|}{ WC } & \multicolumn{2}{|l|}{$\mathrm{HC}$} & \multicolumn{2}{|l|}{ WHR } \\
\hline & $\mathrm{r}$ & $\mathrm{p}$ value & $\mathrm{r}$ & $\mathrm{p}$ value & $\mathrm{r}$ & $\mathrm{p}$ value & $\mathrm{r}$ & $\mathrm{p}$ value \\
\hline \multicolumn{9}{|l|}{ Arabs } \\
\hline FBG & 0.141 & 0.108 & 0.166 & 0.059 & 0.075 & 0.397 & 0.222 & 0.011 \\
\hline $\mathrm{TC}$ & 0.057 & 0.533 & -0.039 & 0.677 & 0.006 & 0.946 & -0.091 & 0.327 \\
\hline $\mathrm{HDL}$ & -0.044 & 0.639 & -0.090 & 0.335 & -0.030 & 0.753 & -0.169 & 0.069 \\
\hline LDL & 0.022 & 0.812 & -0.058 & 0.538 & 0.012 & 0.902 & -0.144 & 0.125 \\
\hline TG & 0.171 & 0.061 & 0.092 & 0.317 & 0.044 & 0.636 & 0.137 & 0.135 \\
\hline TC/HDL ratio & 0.041 & 0.660 & 0.017 & 0.857 & 0.012 & 0.898 & 0.044 & 0.642 \\
\hline \multicolumn{9}{|l|}{ South Asians } \\
\hline FBG & 0.032 & 0.713 & 0.124 & 0.158 & 0.042 & 0.632 & 0.171 & 0.050 \\
\hline $\mathrm{TC}$ & 0.074 & 0.501 & 0.154 & 0.162 & 0.048 & 0.663 & 0.187 & 0.088 \\
\hline $\mathrm{HDL}$ & -0.283 & 0.010 & -0.313 & 0.004 & -0.233 & 0.035 & -0.220 & 0.047 \\
\hline LDL & 0.073 & 0.523 & 0.130 & 0.255 & 0.005 & 0.963 & 0.232 & 0.041 \\
\hline TG & 0.191 & 0.085 & 0.214 & 0.054 & 0.137 & 0.219 & 0.186 & 0.094 \\
\hline TC/HDL ratio & 0.246 & 0.026 & 0.346 & 0.001 & 0.184 & 0.098 & 0.347 & 0.001 \\
\hline
\end{tabular}

of age. For females, ethnicity was not an independent predictor for any of the CVD risk factors, after adjusting for any one of the anthropometric measures BMI, WC, WHR or HC, independently of age.

\section{Discussion}

The studied sample was created from patients of the internal medicine clinic of a general hospital in Kuwait. This sample does not claim to fully represent the entire population. Despite this, because the considered nutritional and metabolic disturbances are endemic across the entire population and because of the variety of reasons for visiting the medical clinic, some careful extrapolations can be deduced from the study, as the mentioned factors tend to make the sample more of a representative one. The smaller number of persons included in the group of South Asian females can, to some extent, be considered a weakness of the study and may likely weaken the strength of some statistical analyses. This smaller number was due to fewer female South Asian volunteers matching the criteria for inclusion into the studied sample.

Based on both gender and ethnicity, Arab males had higher values of all parameters for obesity. In females, the relations were similar, but the difference in WHR did not reach statistical significance. Such findings are not surprising because a high prevalence of obesity among the population of the Persian Gulf had been reported [11]. Despite South Asians being less obese, they demonstrat- ed a stronger tendency toward dyslipidemia. A similar observation had been described in previous studies $[2,3$, 12-14] comparing South Asians to Caucasians and other ethnic groups: South Asians at the same level of obesity have a higher tendency to develop adverse metabolic consequences, leading to premature cardiovascular morbidity and mortality.

Among Arabs, obesity was not a function of age, with the exception of WHR. In South Asians, such a dependence of the degree of obesity on age was highly statistically significant for BMI, WC, HC and WHR ( $\mathrm{p}=0.004$ for BMI, $p<0.001$ for WC and WHR and $p=0.001$ for $\mathrm{HC})$. This fact can be interpreted as obesity in Arabs being established during the first decades of life. Our findings and interpretation are confirmed by the work of AlKandari [15], who described the prevalence of obesity in native Kuwaitis in various decades of life: the heaviest were males between the ages of 30 and 39 years, with females having the highest prevalence of obesity of grades 1 and 2 in the same decade of life. South Asians in Kuwait are, apparently, gradually growing more obese throughout their lives in an affluent society.

When multiple regression analyses were used, ethnicity remained an independent risk factor for TG in the group of South Asian men. In females, this tendency did not reach statistical significance.

Of all of the anthropometric measurements taken (BMI, WC, HC and WHR), BMI showed the weakest ability to correlate with the studied variables. In this aspect, WHR appeared to be the strongest indicator of dyslipid- 
Table 4. Standardized coefficients of independent variables from multiple linear regression analysis using risk factors of metabolic syndrome as the dependent variable

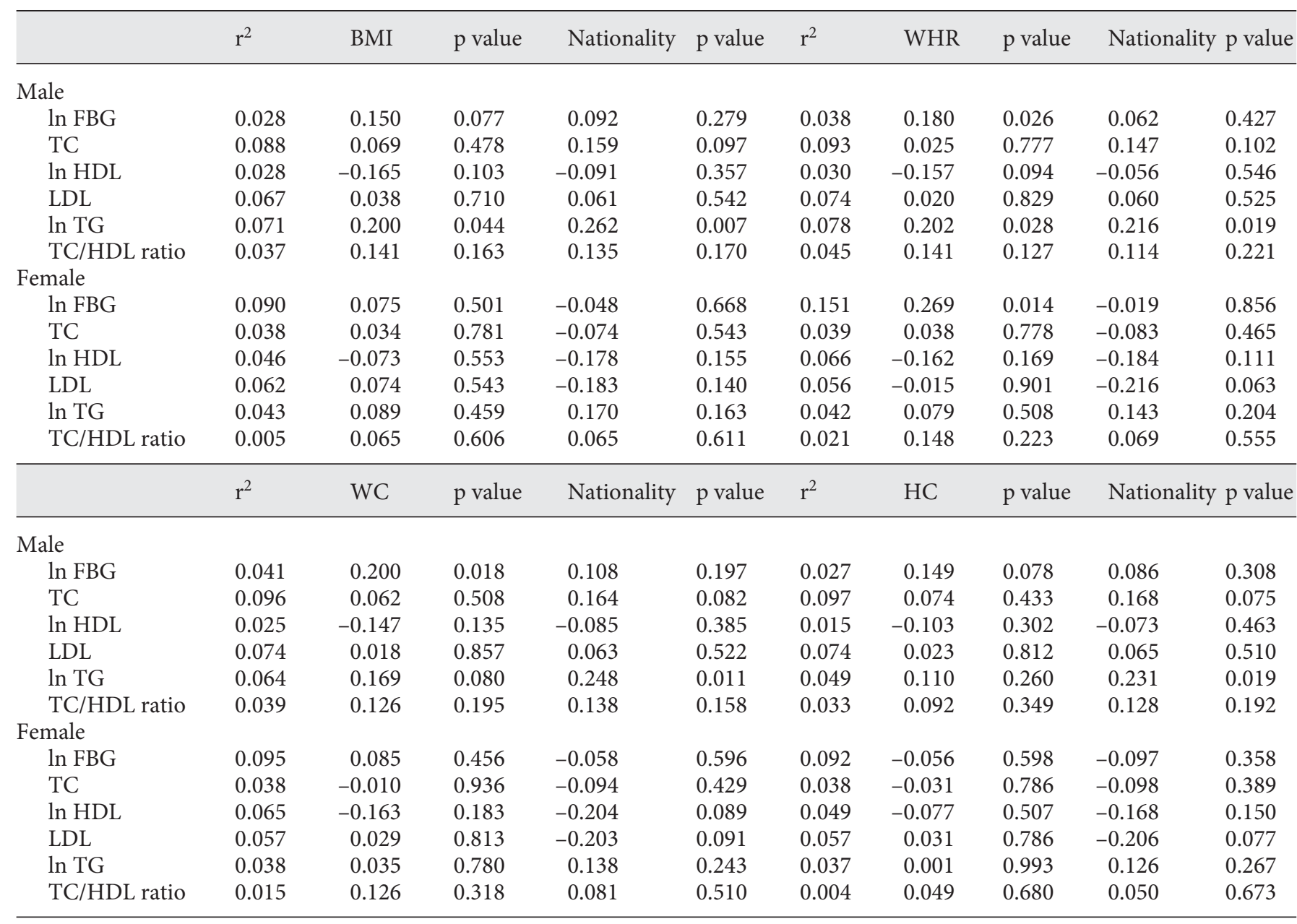

All analyses have been adjusted for age. $\ln =$ Natural logarithm.

emia and impaired glucose metabolism. This finding is not surprising; BMI appeared to be a quite weak predictor of myocardial infarction in both Arabs and South Asians in the INTERHEART study [16]. In contrast, in the same study, WHR proved to be a 3 times better predictor of myocardial infarction than BMI. Very probably, WHR is able to take into account both the amount of pro-atherogenic, intra-abdominal and truncal fat on the one hand and the amount of protective muscular and adipose tissue at the hips on the other. These factors make WHR the most reliable index of obesity for the majority of ethnicities with regard to its metabolic consequences [17]. In one recent study from Kuwait, performed on a cohort of type 2 diabetic patients, BMI showed superior performance compared to all of the anthropometric indices used (BMI,
WHR, WC and waist-to-height ratio) in association with adipokines, C-reactive protein, insulin, insulin resistance and metabolic syndrome. These findings are quite unexpected and might reflect the complexity of the particular aspects of metabolic syndrome [18].

\section{Conclusion}

Arabs and South Asians in Kuwait differed in degree of adiposity. Obesity, primarily the abdominal type, has a different impact on cardiovascular risk factors in each of the two studied ethnic groups. South Asians were more susceptible to the metabolic adverse effects of obesity. Ethnicity was an independent risk factor for increased 
levels of TG in South Asian males. For clinical purposes, WHR proved to be the most reliable simple anthropometric parameter for predicting the adverse impact of obesity on the studied metabolic variables in the two ethnic groups.

\section{Acknowledgement}

The authors wish to thank Ms. D. Gunashekaran and Ms. J. Martiz for their technical help in performing anthropometric measurements.

\section{References}

1 Sundquist J, Johansson SE: The influence of socioeconomic status, ethnicity and lifestyle on body mass index in a longitudinal study. Int J Epidemiol 1998;27:57-63.

-2 Razak F, Anand SS, Shannon H, et al: Defining obesity cut points in a multiethnic population. Circulation 2007;115:2089-2090.

3 Deurenberg-Yap M, Chew SK, Lin VFP, et al: Relationship between indices of obesity and its co-morbidities in multi-ethnic Singapore. Int J Obes Relat Metab Disord 2001;25:15541562.

4 Misra A, Vikram NK, Gupta R, et al: Waist circumference cutoff points and action levels for Asian Indians for identification of abdominal obesity. Int J Obes (Lond) 2006;30: 106-111.

-5 Okosun IS, Liao Y, Rotimi CN, Prewit TE, Cooper RS: Abdominal adiposity and clustering of multiple metabolic syndrome in White, Black and Hispanic Americans. Ann Epidemiol 2000;10:263-270.

-6 Lear SA, Chen MM, Frohlich JJ, Birmingham CL: The relationship between waist circumference and metabolic risk factors: cohorts of European and Chinese descent. Metabolism 2002;51:1427-1432.
7 WHO expert consultation: Appropriate body-mass index for Asian populations and its implications for policy and intervention strategies. Lancet 2004;363:157-163.

$\checkmark 8$ Banerjee D, Misra A: Does using ethnic specific criteria improve the usefulness of the term metabolic syndrome? Controversies and suggestions. Int J Obes (Lond) 2007;31: 1340-1349.

9 International Diabetes Federation: The IDF consensus worldwide definition of the metabolic syndrome. www.idf.org (accessed June 12, 2008)

10 Third Report of the National Cholesterol Education Program (NCEP) Expert Panel on Detection, Evaluation, and Treatment of High Blood Cholesterol in Adults (Adult Treatment Panel III) final report. Circulation 2002;106:3143-3421.

11 Prevalence of obesity in the world. www.who.int/bmi/GraphLegendServlet? $x=$ 1203326667096 (accessed June 4, 2008).

12 Patel S, Unwin N, Bhopal R, White M, Harland J, Ayis SA, Watson W, Alberti KG: A comparison of proxy measures of abdominal obesity in Chinese, European and South Asian adults. Diabet Med 1999;16:853-860.
13 Hughes K, Aw TC, Kuperan P, Choo M: Central obesity, insulin resistance, syndrome $\mathrm{X}$, lipoprotein(a), and cardiovascular risk in Indians, Malays, and Chinese in Singapore. J Epidemiol Community Health 1997;51:394399.

14 Lear SA, Toma M, Birmingham CL, et al: Modification of the relationship between simple anthropometric indices and risk factors by ethnic background. Metabolism 2003;52:1295-1301.

15 Al-Kandari YY: Prevalence of obesity in $\mathrm{Ku}-$ wait and its relation to sociocultural variables. Obes Rev 2006;7:147-154.

16 Yusuf S, Hawken S, Ounpuu S, et al: Interheart Study Investigators: Obesity and the risk of myocardial infarction in 27,000 participants from 52 countries: a case-control study. Lancet 2005;366:1640-1649.

17 Seidell JC, Pérusse L, Després JP, et al: Waist and hip circumferences have independent and opposite effects on cardiovascular disease risk factors: the Quebec Family Study. Am J Clin Nutr 2001;74:315-321.

18 Mojiminiyi OA, Al Mulla F, Abdella NA: Which obesity index best explains the link between adipokines, coronary heart disease risk and metabolic abnormalities in type 2 diabetes mellitus? Med Princ Pract 2009;18: 123-129. 